\title{
El ascetismo musulmán y su tránsito al amor místico.
}

\section{Por: Ingrid Talia Rosas Felguerez.}

La religiosidad musulmana, más allá de las perspectivas meramente literalistas y legalistas, posee un amplio espectro de vida interior o dimensiones espirituales desde sus inicios en el siglo VII, la gran corriente espiritual que atraviesa todas estas dimensiones se ha denominado en su conjunto de formas como "sufismo". Esta corriente en los primeros tiempos del islam, se conformaba por movimientos predominantemente ascéticos, sobre todo a mediados del siglo VII al siglo IX; cuyas actitudes devocionales particulares de alguna forma desembocaron en el desarrollo de un misticismo en rigor.

No me cabe ninguna duda de que, como señala la erudita en misticismo islámico Annemarie Schimmel, la mística puede definirse como "amor al Absoluto, pues la fuerza que separa el verdadero misticismo del simple ascetismo es el amor". ${ }^{1}$ Mi hipótesis 1 precisamente plantea que tal elemento del "puro amor" es lo que vuelve la piedad de la vía ascética hacia la piedad de la vía mística. ¿Cómo ocurre esto y en qué consisten las actitudes devocionales de cada vía dentro del contexto que nos atañe? Es lo que trataré de contestar a continuación.

Pero antes, es importante señalar que el complejo, extenso y pluriforme fenómeno de la profesión del tasawwuf, que se ha traducido como sufismo, se refiere específicamente a la vida mística-ascética o "la dimensión interna del islam", ${ }^{2}$ es pues, sinónimo de 'misticismo islámico'. 'Sufí', por lo tanto, es el equivalente árabe, persa y turco, de 'místico', es el místico que profesa la fe musulmana. De tal suerte que no podemos sustraer tal complejo de corrientes místico-ascéticas de las raíces de su propia tradición sin que se

\footnotetext{
${ }^{1}$ Annemarie Schimmel, Las dimensiones místicas del islam, trad. Agustín López Tobajas y María Tabuyo Ortega, Madrid: Trotta, 2002, p. 20.

${ }^{2}$ Annemarie Schimmel, Introducción al sufismo, trad. Lía Tummer, Barcelona: Kairós, 2007, p. 9.
} 
pierda su sentido histórico específico y sin oscurecer nuestro conocimiento sobre su esencia verdadera.

Como ocurre con otras tradiciones religiosas, el misticismo islámico presenta a lo largo de su historia una extensa multiplicidad de manifestaciones o facetas, a tal grado que resulta prácticamente irrealizable la tarea de explicar y describir este hecho de manera definitiva. No obstante, existe una orientación y raíz común, que le da unidad y hacia la que se dirigen toda esa variedad de sufismos $^{3}$, haciendo posible hablar de una tradición particular.

La investigación occidental del tema suele distinguirse a menudo por presentar una amplia discusión sobre las influencias que hicieron posible el misticismo dentro de este sistema religioso en especial; solía presentarlo como una manifestación ajena al islam oficial y jurídico, al punto de considerarlo "una planta extranjera" en ese suelo arenoso, aunque actualmente no cabe duda de que estamos frente a un fenómeno autóctono.

La discusión sobre las influencias que dieron origen al sufismo es verdaderamente amplia. Desde luego, no cabe duda de que el sufismo desde sus comienzos ha estado influido por otras corrientes místicas; se ha destacado la influencia del neoplatonismo, del hinduismo y, en especial, de la espiritualidad de los anacoretas cristianos del desierto, entre otras. Sin embargo, la posibilidad de vida mística y ascética dentro del islam no se termina de explicar aludiendo únicamente a influencias externas. Además, como advierte Annemarie Schimmel, resulta difícil, sino es que imposible, rastrear con exactitud esas influencias pues formaban parte del ambiente cultural, "de algún modo flotaban en el aire". ${ }^{2}$

Hoy en día, no cabe ninguna duda de que se pueden comprender y explicar las doctrinas sufíes de manera más satisfactoria a partir de sus raíces coránicas. Reitero el sufismo es un fenómeno autóctono, se trata, en palabras de Henry Corbin, de la

\footnotetext{
${ }^{3}$ Jean Chevalier, El sufismo, trad. José Barrales Valladares, México: FCE, 1987, p. 9.

${ }^{4}$ Annemarie Schimmel, Introducción al sufismo, p. 20.
} 
"fructificación del mensaje espiritual del Profeta, el esfuerzo de revivir personalmente sus modalidades, mediante una introspección del contenido de la Revelación coránica". ${ }^{5}$ Es decir, los mensajes y el milagro mismo del Corán, así como la propia vida de Muhammad incitan una exploración íntima y personal del islam.

El desarrollo de una espiritualidad interior dentro de las religiones supone siempre una búsqueda del sujeto por interiorizar los hechos clave de la historia de su propia tradición religiosa, éstos corresponden con su camino espiritual. A partir de su propia vivencia personal, del despertar de su espíritu, una vez que han reproducido en sí mismos el acontecimiento histórico de la Revelación, los místicos descubren el significado definitivo y real de la verdad religiosa. En el caso del islam, por ejemplo, la asunción del Profeta a los cielos, mi'raj, la noche en la que Dios le eleva hasta Su Presencia es el modelo de ascensión espiritual que el sufí anhela realizar.

Ahora bien, entrando de lleno al tema que me compete. Se sabe poco sobre las prácticas ascéticas de los primeros sufíes, es hasta que la dinastía de los Omeyas 3 presuntamente usurpa el poder cuando comienzan a evidenciarse diversas brechas dentro de la creciente comunidad musulmana.

En este sentido, el desarrollo de la ascesis en el islam, predominantemente en Siria, capital omeya, y en las ciudades iraquíes, Kufa y Basora, también se presentó como una respuesta ante los acontecimientos políticos generando una fuerte oposición al gobierno, específicamente a partir de tal acontecimiento. La rápida expansión del territorio islámico patentiza una apetencia de dominio y riquezas contradictoria con la realidad modesta de los primeros musulmanes y con las azoras del Corán que tratan sobre el aspecto perecedero de las cosas del "mundo inferior", el ámbito en el que se desenvuelve la vida humana,

\footnotetext{
${ }^{5}$ Henry Corbin, Historia de la filosofía islámica, trad. Agustín López, María Tabuyo y Francisco Torres Oliver, Madrid: Trotta, 1994, p. 175.
} 
contrapuesto a la perenne morada del Creador, "el otro mundo", la vida después de la muerte, es decir, la verdadera Vida. ${ }^{6}$

De tal suerte, que a medida que aumentaba la opulencia igualmente lo hacía, como resistencia, y con verdadero sentido crítico, el espíritu de frugalidad practicado por los cada vez más numerosos círculos de devotos a lo largo del Imperio creciente.

Los ascetas seguían escrupulosamente la ley musulmana, inspirados por el ejemplo del Profeta Muhammad y por algunos compañeros que le rodearon, también suelen ser mencionados en la cadena de iniciados de las órdenes sufíes, y se convirtieron en modelos de piedad mística y ascética. La figura de Jesús, por otro lado, reconocida también en el Corán, se convierte, asimismo, en ejemplo perfecto de asceta, los dichos y hechos sobre sus enseñanzas y el ejemplo de su vida modesta y errante, como se retrata en la literatura ascética sufí, mueven hacia la caridad y a la renuncia de lo material con la confianza en que Dios suministra a sus criaturas; se llegó a hablar, incluso, entre estos devotos de "la vía de Jesús", ${ }^{7}$ y aún se le considera en el sufismo como "médico de los corazones". 8

Como señale hace un momento, muchos autores declaran que la vía ascética $(z u h d)$ o la vía de renuncia, practicada en aquella época por estos grupos de creyentes se vio fuertemente influida por la ascesis de los anacoretas cristianos que mantenían contacto con los beduinos antes del islam. La especial devoción a Jesús en esta etapa del sufismo y la concepción que se tenía de él, cuyas cualidades son las de un monje, suele ser un apoyo para quienes resaltan en sus argumentaciones esta influencia.

No obstante, como ya expliqué, son evidentes las raíces coránicas del sufismo, de modo que las prácticas y actitudes de tales movimientos ascéticos se pueden explicar de manera más satisfactoria como respuestas a los mensajes del Corán y a la figura del Profeta, aun cuando compartían con aquellos eremitas el mismo aborrecimiento por las cosas mundanas y fugaces de la vida.

\footnotetext{
${ }^{6}$ V. gr.: Corán 29, 64.

${ }^{7}$ Félix M. Pareja, La religiosidad musulmana, Madrid: B. A. C., 1975, p. 264.

${ }^{8}$ Annemarie Schimmel, Introducción al sufismo, p. 19.
} 
Hasan al-Basri (643-728), es la persona bajo la cual se condensan algunas de las más definidas vocaciones ascéticas de los primeros tiempos del sufismo. Desde una perspectiva historiográfica es considerado el patriarca del misticismo musulmán. ${ }^{9} \mathrm{Me}$ resulta fundamental mencionarlo pero por cuestiones de espacio omitiré detalles sobre su vida, me limito a mencionar algunos aspectos que describen muy bien el tipo de espiritualidad que predicaba.

Particularmente, entre los sufíes de aquel entonces, resonaban con fuerza las azoras que hablan sobre el día del Juicio y la condena en el fuego del infierno. En la literatura ascética musulmana, más que en el mismo Corán el infierno y sus castigos suelen describirse de formas explícitas por lo que estas actitudes religiosas se caracterizaban preeminentemente por un temor a Dios (taqwa), al infierno y a la muerte, ${ }^{10}$ penitencia por los pecados cometidos, añoranza por el Paraíso, arrepentimiento (tawba) o conversión, tristeza ( $h u z n$ ) y llanto, contrición ( $k a m a d$ ), es decir, la conciencia de la culpa y del pecado, la búsqueda de serenidad y paz. Así pues, el temor se convirtió en un fuerte móvil hacia la esperanza de la salvación y hacia la práctica de la purificación; el sufrimiento y tristeza permanentes, se convirtieron en una señal de amor divino.

Entre las prácticas frecuentes de los ascetas se encontraban los ayunos, el retiro espiritual, el abandono de los bienes, la oración ritual, añadiendo especial atención a la meditación ( $f i k r)$ y rezo nocturnos, aunque la vigilia de oración no está prescrita dentro de las cinco oraciones diarias es significativamente importante en las prácticas del sufismo desde sus comienzos, pues guarda una simbólica relación con la noche en la que el Profeta viaja y asciende a los cielos.

Hay otros aspectos que valdría la pena mencionar pues, como en todos los casos, las manifestaciones del ascetismo pueden ser muy diferentes entre sí, aunque el objetivo es el mismo, desnudarse de los todos los velos que cubren la senda que lleva a Dios.

\footnotetext{
${ }^{9}$ Ibíd., p.45.

${ }^{10}$ Ibíd., p. 22.
} 
Poco a poco, también fueron distinguiendo y sistematizando las fases o grados de su proceso de ascensión espiritual simbolizado, al igual que en otras tradiciones religiosas como una vía, un camino o un viaje (tariqa). Estas fases paulatinamente desembocaron en las etapas de la vía mística; lo cual tiene que ver con la distinción sufí entre las estaciones (maqmat) y estados (ahwal).

Establecieron escalas de ascensión interior a partir de sus propias experiencias espirituales y de la observación del trayecto del alma por la tariqa, basados, asimismo, en las prescripciones coránicas y en la propia vida del Profeta; a lo largo del progreso de su tradición fueron perfeccionándolas y sistematizándolas, de modo que, a pesar de existir muchas de estas gradaciones, entre los manuales sufíes es posible identificar peldaños o estaciones que no varían de una escala a otra.

La etapa o estación (maqam) puede lograrse por medio del esfuerzo e intención personal, aunque no se excluye completamente el auxilio divino, una vez que se obtiene el dominio total de una se puede ascender a la siguiente. Se trata de fases duraderas, las maqamat son actos $\mathrm{y}$, como señalan del mismo modo Schimmel $^{11}$ y Nicholson ${ }^{12}$, "constituyen una disciplina ascética y moral" con la que el viajero (salik) debe comprometerse plenamente para realizar su progresiva purificación de todas las ataduras y velos que puedan impedirle dedicarse únicamente a Dios; son técnicas que ayudan a pulir el espejo del corazón y del alma para que logren reflejar la belleza y la esencia pura de Allah. De tal suerte que ya superado un peldaño no debe darse marcha atrás al anterior, ni tampoco permanecer en el estancamiento.

En cuanto a los ahwal (en singular hal) o estados, estos son disposiciones espirituales, sentimientos, que no pueden ser retenidos por mucho tiempo, lo que corresponde con la característica de transitoriedad que William James le atribuye a los estados de conciencia místicos. Asimismo, cumplen con el rasgo de la pasividad, pues son donaciones gratuitas de Dios, dependen de la voluntad y favor divinos, no se logran, menos

\footnotetext{
${ }^{11}$ Annemarie Schimmel, Las dimensiones místicas, p. 117.

${ }^{12}$ Reynold A. Nicholson, op. cit., p. 46.
} 
se controlan por voluntad o poder personal, cuando acaecen no se pueden detener ni contener, tampoco rechazar por el propio esfuerzo. Aunque algunos sufíes llegaron a discutir si efectivamente eran fugaces o podían retenerse por un tiempo, de igual modo se polemizó si algunas etapas se tratan más bien de estados o viceversa. ${ }^{13}$

La progresión de las maqamat puede variar entre las escalas de los teóricos sufíes, así como la cantidad de peldaños a escalar, en el tránsito por esta vía también existen como variables la capacidad del murid (aquel que tomó la decisión de comenzar el camino) y las concesiones de Dios que, ya hemos visto, son, en cierto sentido, accidentales. De lo que no cabe discusión es que debe llegarse hasta el último peldaño de la escala con total atención y entrega desinteresada al viaje. De modo que los estados corresponden específicamente con una espiritualidad propiamente mística, las etapas se refieren a una piedad práctica, es decir: ascética.

El temor al infierno y la melancólica esperanza del paraíso que predominaban en el ambiente de sobriedad de los ascetas musulmanes, pronto se transmutó en amor absoluto y desinteresado, el camino directo hacia la mística. "El amor que lleva en sí mismo su razón de ser se convirtió en el tema central del sufismo" ${ }^{14}$ gracias a una mujer, la eminente Rabi‘a al-Adawiyya (721-801), santa de Basora. A partir de ella queda claro que el misticismo sin amor es pura ascesis.

Se le atribuyen muchos prodigios y hechos milagrosos, el resplandor espiritual que irradiaba, iluminaba sus noches haciéndola prescindir de velas. ${ }^{15}$ Los dichos, así como los cantos, poemas, las danzas y la música creados por Rabi‘a, están repletos de ese amor ardiente y puro que fascina a toda la atención y que penetra en todas las dimensiones del ser descubriendo el único deseo insondable y natural de trascendencia. El paraíso prometido y la condena del infierno, en la espiritualidad de la santa son velos que cubren la belleza de Dios; por eso ella decía que quería prenderle fuego al primero y arrojarle agua al segundo,

\footnotetext{
${ }^{13}$ Annemarie Schimmel, Las dimensiones místicas, p. 117.

${ }^{14}$ Ibíd., p. 54.

15 Malek Chebel, op. cit., p. 102.
} 
de modo que sólo quede alabar al Creador por amor, no por temor, ni por la búsqueda de la recompensa de la salvación estos motivos no dejan de ser interesados. El único interés de la mística es adorar a Dios, sólo a Dios por sí mismo, por su hermosura sin más.

Rabi'a escribe en uno de sus poemas que conforme a dos amores ama a Allah: el primero es un amor interesado, lo hace para su propia felicidad, en éste sus pensamientos se ocupan exclusiva y absolutamente de Él. El segundo, el amor del cual Dios es digno, tiene su motivación sólo en el deseo de ver su rostro y contemplarle más allá de sus velos. En ambos, ella se abandona completamente, no queda más en su ser que venerar y contemplar únicamente a Dios. ${ }^{16} \mathrm{El}$ amor diluye el recuerdo de infierno y paraíso, incluso la apariencia o todo rastro de un yo, no hay gloria para ella, "todo es Él".

Al parecer queda claro que la meditación de Rabi‘a sobre la sura 5,54 del Corán que declara el amor recíproco entre Allah y los seres humanos, alumbró la espiritualidad de la santa y las doctrinas sobre el amor místico de los sufíes que le sucedieron. ${ }^{17}$ En sus poemas y cantos ella identifica esta promesa amorosa con imágenes sobre el amor profano, lo que se volvió con el tiempo un tópico de la tradición literaria sufí así como muchas de sus expresiones y enseñanzas. Rabi ‘a, también hizo de la oración nocturna de los primeros ascetas una conversación íntima con Allah, "la noche del Destino" se convirtió en el escenario que envuelve la unión de los amantes. El Dios juez de la predicación de los ascetas, poco a poco empezó a convertirse en el Dios amigo, en el Amado del camino del misticismo.

Aunque fue hasta los inicios de la dinastía 'Abbasí que comienza desarrollarse concretamente la tasawwuf o mística, ${ }^{18}$ cuando el territorio del imperio islámico aumentó al punto en el que los intercambios culturales con otras tradiciones religiosas eran frecuentes, influyendo de muchas formas en la espiritualidad ascética de los primeros místicos musulmanes, aunque en la espiritualidad de Rabi ${ }^{`}$ a tenemos el paso decisivo.

\footnotetext{
${ }^{16}$ Jean Chevalier, op. cit., pp. 31-32.

${ }^{17}$ Annemarie Schimmel, Las dimensiones místicas, p. 55.

${ }^{18}$ Montserrat Abumalham, op. cit,.p. 156.
} 


\section{CONCLUSIÓN}

La presencia del elemento del "puro amor" reconfigura las actitudes devocionales de la ascesis dando lugar a un misticismo en rigor pues de alguna manera cambia el sentido de la búsqueda por Dios, la motivación parece más íntima y desinteresada, como bien ilustra el gran místico del islam Maulana Rumi:

"Hay dos clases de camino. Los ciegamente religiosos

llegan contra su voluntad. Los otros obedecen por amor.

Los primeros tienen intereses:

desean tener cerca a la nodriza porque les da leche.

Los otros aman a la nodriza por su belleza.

Los primeros memorizan los ensayos

de la conformidad y los repiten.

Los segundos desaparecen donde quiera que Dios los llame.

Ambos son sacados del manantial.

Cualquier movimiento es de quien mueve, cualquier amor es de quien ama." 19

El amor puro implica renuncia al nafs el aspecto humano que nos lleva a la concupiscencia o a la debilidad moral, llevando al sujeto más allá del esfuerzo e intención personales.

Ya se ha visto brevemente en la distinción entre estados y etapas, las relaciones que la mística guarda con la ascesis, ambos son caminos íntimamente ligados. Entre los místicos del islam llegó a discutirse ampliamente el papel de la vía ascética como aspecto definitorio del sufismo, pero para algunos de ellos la vía sufí está más allá de las meras prácticas y formas de vida encaminadas a la renuncia, al hallarse suscitada y

19 Jalaludin Rumi, La sed de los peces, versión e introducción de Elisa Ramírez Castañeda, México: CONACULTA, 2005, p. 56. 
completamente guiada por las concesiones de la gracia divina. El misticismo como la experiencia de unión con Dios, en última estancia, logra su consumación por obra de la Gracia, sin importar cuantos grados de purificación haya logrado el devoto por mérito propio.

Lo que me lleva a un segundo punto: las prácticas ascéticas, las técnicas para generar diversos estados de conciencia, son parte de la disciplina moral y espiritual, y en la vía mística no tienen ningún sentido o razón de ser sin la idea previamente consentida de una Presencia, categoría que supone la unidad entre sujeto y objeto, una realidad absolutamente trascendente a la humana y que por eso al mismo tiempo es inherente a ella, a nosotros mismos. ${ }^{20}$ En esa Presencia y en la respuesta a ella, Juan Martín Velasco ve el corazón de la religión, y por lo tanto, la raíz de la mística que, "en relación con la conciencia y la dimensión afectiva de la persona, primero es presentida o añorada, después buscada, y por último percibida, padecida y disfrutada por el sujeto". ${ }^{21}$

Así pues, el papel de la perfección ascética pasa a ser todo menos que un objetivo, 10 lo mismo con los estados de conciencia señales del ascenso espiritual del viajero. Son medios, instrumentos con el único propósito de que la totalidad del practicante se convierta en un receptáculo dispuesto al contacto con lo divino, no son más que vías de purificación. El místico tiene un completo desprendimiento respecto a todos esos medios, no busca "los beneficios de carácter psicológico y afectivo que puedan reportarle"22.

El ascetismo en la vía mística funciona como una propedéutica para disponer todas las dimensiones de la persona al acogimiento de dicha Presencia que, en última instancia, se donará gratuitamente, o incluso se impondrá ante el sujeto; las prácticas ascéticas no son las causas que propician la unión o las acciones que le llevarán a ser una "mejor persona".

En otras palabras, la práctica constante, el ayuno o la renuncia, son importantes para crear el ambiente o las circunstancias propicias para que ocurra el divino accidente; pero

\footnotetext{
${ }^{20}$ Juan MartínVelasco, op. cit., p. 254.

${ }^{21}$ Ibíd., p. 316.

22 Juan MartínVelasco, op. cit., p. 316.
} 
cuando ocurrirá y cómo, o si ocurrirá es un hecho imprevisible. La unión que anhelan los místicos es una irrupción completamente fortuita en la vida de las personas.

De modo que el amor puro tampoco es un fin, es un medio y la motivación más elevada para lograr una comunión perfecta con lo divino. Considero que el elemento definitorio del misticismo es precisamente el amor puro al Absoluto, la mística en su significación más amplia es amor en este sentido, pues contiene en él la esencia de la unión mística con Dios.

Desde luego, hay distintos elementos y condicionantes externas, como el influjo de la cultura o las variantes de los hechos históricos, que motivaron el tránsito de una piedad predominantemente ascética a una mística en la religiosidad islámica; no obstante, en el fondo de la vida espiritual de esta tradición religiosa la meditación sobre el amor, como manifestación del pacto que Dios ha hecho con su creación es la médula del desarrollo de las actitudes devocionales.

Desde los primeros pasos en la vía que lleva a la unión, la llama del amor se encuentra encendida en el corazón del buscador, la búsqueda es amorosa también. "Ni un solo amante buscaría la unión si el amado no la buscara" ${ }^{23}$, escribe Maulana. La verdadera mística es una relación de amor y toda relación de este tipo es mutua. El puro amor evidencia que el amor de Dios antecede el amor del ser humano hacia él, es decir, el deseo de unión del sujeto es realmente un deseo de Dios y este hecho es el tránsito directo de la mera ascesis a la mística. El amor puro es también un recuerdo del pacto o alianza que el Creador ha hecho con su creación el día del alast $^{24}$, reminiéndolo a retornar al no-ser a partir de lo cual todo fue creado.

Por ello tal elemento es la gracia primordial para casi todos los sufíes después de Rabi‘a, con su introducción a la espiritualidad sufí cambian las actitudes devocionales de manera profunda adquiriendo interesantes grados de complejidad; por ejemplo, a pesar del

\footnotetext{
${ }^{23}$ Annemarie Schimmel, Las dimensiones místicas, p. 156.

${ }^{24}$ Corán: 7,172.
} 


\section{ARTÍCULOS}

constante dejo de añoranza siempre presente en el sufismo, muy a menudo también este amor divino adquiere distintos matices de éxtasis y alegría lo que se expresa muchas veces en la poesía con la metáfora de la ebriedad, con el paso del tiempo se desarrolla la danza del sema, el fikr se transforma en una comunicación íntima con el Amado, así mismo, comienza a surgir una erótica de lo divino.

Para finalizar, considero que este es el mensaje de amor y el significado de la alianza primordial entre Allah y el ser humano: "buscas lo que eres". 